\title{
DESENVOLVIMENTO SUSTENTÁVEL NAS ORGANIZAÇÕES COMO OPORTUNIDADE DE NOVOS NEGÓCIOS
}

\section{SUSTAINABLE DEVELOPMENT IN ORGANIZATIONS AS A NEW BUSINESS OPPORTUNITY}

\author{
Macsuel Miranda de Oliveira * \\ macsuelmiranda@gmail.com \\ Maria Helena Amaral da Silva Medeiros* \\ tianenaamaralml@yahoo.com.br \\ Rosângela Leopoldino da Silva * \\ pretazanza2009@hotmail.com \\ Giovana Azevedo Pampanelli Lucas * \\ giopampanelli@gmail.com \\ * Faculdade Sul Fluminense,Volta Redonda/RJ - Brasil
}

\begin{abstract}
Resumo
A sustentabilidade pode ser entendida como a convivência harmoniosa do homem com a natureza. $\mathrm{O}$ objetivo do presente estudo é identificar como uma empresa pode crescer em termos econômicos adotando práticas de sustentabilidade. Para alcançar o objetivo proposto, o trabalho tem como finalidade analisar a responsabilidade dos indivíduos e das organizações ao que se refere à preservação do meio ambiente. As organizações têm como desafio encontrar soluções para ajustar crescimento as possibilidades de produção da natureza, e estabelecer critérios e parâmetros adequados para atender práticas de responsabilidade social, contribuindo assim, para a construção de uma sociedade mais justa e igualitária. O desenvolvimento de novas tecnologias, e novos processos que permitem um crescimento econômico com utilização de menos matéria-prima e a redução de recursos naturais beneficiam o meio ambiente e atrai a atenção do consumidor, o qual opta por empresas ambientalmente corretas. Os resultados do estudo apontam que, os investimentos em práticas sustentáveis proporcionam credibilidade para as organizações diante de seus stakerholders e retornam para a organização através de vantagem competitiva, evidenciados pela Empresa citada no estudo de caso, que compatibiliza crescimento econômico e sustentabilidade, através da inovação em seus processos e novas tecnologias.
\end{abstract}

Palavras-Chave: Sustentabilidade; Crescimento Econômico; Responsabilidade Social.

\begin{abstract}
Sustainability can be understood as the harmonious coexistence of man with nature. The aim of this study is to identify how a business can grow economically by adopting sustainability practices. To achieve the proposed objective, the work aims to analyze the responsibility of individuals and the organizations referred to the preservation of the environment. Organizations are challenged to find solutions to fit the growing nature of the production possibilities, and establish appropriate criteria and parameters to meet social responsibility practices, thus contributing to building a more just and egalitarian society. The development of new technologies and new processes that allow economic growth with less use of raw materials and the reduction of natural resources benefit the environment and attracts consumer attention, which opts for environmentally friendly companies. The study results show that investments in sustainable practices provide credibility to organizations before their stakerholders and return to the organization through competitive advantage, as evidenced by the Company mentioned in the case study, which reconciles economic growth and sustainability through innovation in its
\end{abstract}


processes and new technologies.

Keywords: Sustainability; Economic growth; Social responsability.

\section{INTRODUÇÃO}

Ser sustentável é viver de forma responsável com o planeta, para que esse seja capaz de suportar os impactos que o ser humano exerce nele ao longo da vida. É preservá-lo para as futuras gerações.

A exploração de áreas ou recursos (naturais ou não) deve ser feita de forma a prejudicar menos o possível o equilíbrio entre meio ambiente e comunidades. O termo sustentabilidade está cada vez mais presente no âmbito empresarial e na sociedade, no entanto, poucos compreendem o que seja associandoo à preservação do meio ambiente. Porém, pode ser compreendido, de forma incompleta, pois, a sustentabilidade nada mais é que a relação harmoniosa das sociedades humanas com a natureza, e com as comunidades.

A sustentabilidade gera inúmeros benefícios para empresa, pois o consumidor sente-se atraído pelas empresas verde, uma vez que este cada vez mais informado opta por consumir produtos e serviços de empresas ambientalmente corretas. Os consumidores preferem comprar em redes varejistas que promovem ações ambientais, e pagam mais por produtos ecologicamente corretos, a prática da sustentabilidade traz para organização os mais variados benefícios, como redução de custos e riscos, reduz os desperdícios e gera lucros, melhora o relacionamento com o consumidor, e transmite uma imagem de empresa saudável e confiável, a valorização das ações em bolsas de valores, pois os investidores preferem investir em ações de empresas sustentáveis ambientalmente.

A sustentabilidade torna-se uma questão de atitude, estratégia e inovação, proporcionando maiores chances benéficas e rentáveis, para empresa e seus stakeholders. Segundo o Instituto Brasileiro de Sustentabilidade (INBS, 2015) "o documento de Brundtland de 1987 intitulado Nosso Futuro Comum, o desenvolvimento sustentável é aquele que atende às necessidades presente sem comprometer a capacidade das gerações futuras atenderem suas necessidades". Segundo (CHAMBERS, et al 2000 apud BELLEN et al 2004)," a maioria das análises considera o meio ambiente como externo, separado das pessoas e do mundo do trabalho, um fato decorrente de herança cultural e ética". O autor afirma que o mundo natural não pode ser separado do mundo do trabalho.

O relatório de Brundtland (1987) e o autor Chambers (2000) concordam entre si em vários pontos relevantes, porém, o relatório desperta atenção para uma base conceitual de que a sustentabilidade é o uso dos serviços dentro do principio da manutenção do capital natural, ou seja, o 
aproveitamento dos recursos naturais dentro da capacidade de acumulação, pois, o uso excessivo dos recursos naturais, provocados pelos padrões de consumo do homem contemporâneo coloca em risco a assistência das futuras gerações.

Chambers (2000) faz uma análise de como se considera o meio ambiente, e afirma que não se pode existir externo, ao se falar de matéria e energia não existe o termo externo, o meio ambiente faz parte de um todo, sociedade, trabalho, família. A sustentabilidade reivindica que se passe da gestão dos recursos para a respectiva humanidade, e que a sociedade deve se adequar aos padrões de vida, dentro dos limites impostos pela natureza.

Segundo a Revista Canção Nova (2016 p.11). "Se nós não fizermos algo urgente sobre saneamento básico no Brasil, a poluição nossa vai ser também nossa punição e vai representar a destruição da vida no planeta terra, porque não temos outro habitat". Diante disso, entende-se que não é uma opção cuidar do meio ambiente, e sim uma questão de sobrevivência, pois, essa é a nossa casa a única que temos.

A sustentabilidade nas organizações pode ser vista como inúmeras oportunidades, inovar dentro do próprio negocio ou buscar novos mercados. Inovar dentro do próprio negocio significa sair á frente da concorrência e, por tanto, garantir a sobrevivência da organização, e o seu crescimento.

As organizações que se preocupam com impacto social de suas ações, e priorizam investimentos que contribuam para o desenvolvimento humano, atraem atenção do consumidor que se tornam fieis aos seus produtos ou serviços, revertendo essas ações e parcerias em lucros para a organização.

Expandir para comunidades de baixa renda, e para o interior é uma oportunidade, em especial para pequenas empresas, uma vez que as grandes corporações ignoram ou desconhecem suas necessidades, os benefícios são vários, como incentivos fiscais, e em muitas situações consumidores que vivem longe dos grandes centros comerciais, tanto o acesso a essas categorias como a sofisticação do consumo, proporcionam crescimento para a organização, essa poderá apoiara comunidade na geração de empregos e renda, contribuindo assim, com o crescimento local. Diante disso, cabe questionar: como produzir, consumindo menos recursos e sendo, ao mesmo tempo, lucrativo?

Diante do exposto, o artigo proposto tem como objetivo geral, identificar como a empresa pode crescer economicamente dentro das práticas da sustentabilidade. E como objetivos específicos, entender como o desenvolvimento sustentável contribui com o equilíbrio ambiental; analisar como o desenvolvimento sustentável reduz os custos na organização; identificar como o desenvolvimento sustentável atrai o consumidor.

Nos dias atuais, os novos recursos tecnológicos permitem uma maior produção utilizando menos matéria prima, e a redução também dos recursos naturais como energia e água. As empresas devem se adequar a 
realidade e buscar alternativas como destinar corretamente os resíduos, assim, o que seria descartado passam a ser mais uma fonte de renda. Portanto, passa a ser um ponto positivo economicamente, e essa utilização dos recursos com responsabilidade causa menor impacto ambiental e preserva-se o ecossistema. As empresas que agem corretamente dentro das politicas e leis ambientais contribuem com a preservação do planeta e não têm despesas com multas. Essas atraem atenção dos consumidores através de suas praticas de responsabilidade social e ambiental, investimentos em educação ambiental para os colaboradores e comunidades, essas ações torna a empresa mais responsável e confiável aos olhos dos consumidores, e acabam ganhando novos clientes.

Como metodologia, utiliza-se de uma pesquisa bibliográfica, a fim de entender o que a literatura mostra sobre esta temática. Será efetuado um recorte de estudo de caso correlatado com este estudo para que se possa estabelecer uma discussão crítica a respeito do assunto. Ao final realização deste estudo, espera-se contribuir com pesquisas nessa área, bem como os cursos de administração, e afins.

O presente trabalho foi dividido em quatro tópicos, não considerada a introdução do material. O tópico um aborda desenvolvimento sustentável; o tópico dois sintetiza ética nas organizações; o tópico três explica a importância da educação ambiental nas organizações; por fim o tópico quatro apresenta a gestão ambiental nas organizações como oportunidade de novos negócios com foco no desenvolvimento do assunto abordado; e como quinto tópico o trabalho apresenta um estudo de caso já existente. Finalizando, apresenta o caminho metodológico, as características do estudo, seguindo uma breve análise crítica e/ou resultados e as conclusões finais.

\section{DESENVOLVIMENTO SUSTENTÁVEL}

Diante de uma crescente população mundial, onde se incentiva a um consumo desenfreado, a sociedade deve deslocar o foco do crescimento econômico continuo para um maior comprometimento com o meio ambiente, as organizações tem como desafio encontrar soluções para ajustar crescimento às possibilidades de produção da natureza.

Segundo Brown (2003 p.14 apud NASCIMENTO et al, 2012), "que a economia está em conflito com os sistemas naturais do planeta é uma evidência que ressalta das informações cotidianas sobre o desaparecimento das zonas de pesca, a redução das florestas, a erosão do solo... e o desaparecimento das espécies". Segundo o autor a gravidade da crise ambiental revela a degradação das condições de vida em nosso planeta, caso não haja mudanças, é possível que aconteça uma extinção no planeta, percebe-se, que o modelo de produção e consumo põe em risco não só o ambiente, mas a qualidade de vida dos seres humanos. 
A definição mais propagada de desenvolvimento sustentável é da comissão de Brundtland (Nosso Futuro Comum, 1987 apud INBS, 2015), esse defende que “o desenvolvimento sustentável é aquele que satisfaz as necessidades atuais sem comprometer as possibilidades de satisfazer as necessidades das gerações futuras". O relatório propõe mudanças, que implica alterações das relações econômicas e sociais, aproveitamento dos recursos naturais dentro de seus limites, preservando assim, os ecossistemas, a manutenção dos processos ecológicos, e toda espécie de vida, principalmente humana. Aborda-se, a necessidade de inclusão dos países mais pobres, junto as grandes economias, propõe mudanças envolvendo o meio ambiente, importância da participação política, e sugere um equilíbrio entre o uso dos recursos e o crescimento.

Segundo Elkington (2001 p.74 apud ESTENDER et al, 2010 p.22 ), “dez anos após a comissão de Brundtland, viu-se que somente a resolução de questões ambientais que tanto afligiam a sociedade e o meio organizacional - não resolveria os problemas de uma economia global sustentável. Seria necessário atingir outros meios para se conseguir a sustentabilidade". A sustentabilidade não pode ser vista como um controle apenas da poluição, o problema está muito além. Percebe-se, então, que o problema a ser tratado não é somente ambiental ou econômico, e sim, um problema social.

De acordo com o plano apresentado na ECO-92, da agenda 21, para atingir um desenvolvimento sustentável deve-se focar em três áreas, que influenciam diretamente o desenvolvimento, são elas, econômica, social, e ambiental. Essas três constituem o denominado tripé da sustentabilidade (triple botton line).

Defende Almeida (2005 apud REVISTA CLASSE MUNDIAL et al, 2005: p.17):

No termo o botton line representa a saúde do planeta, sem a qual atividade econômica e a própria vida se inviabilizam. O tripé se constitui em posturas, objetivos e processos que toda companhia deve adotar para criar valor econômico, social, e ambiental e minimizar os danos de sua atuação.

Pois, essas são o principal apoio, a sustentabilidade está atrelada ao desenvolvimento das mesmas. Nota-se, que um país em desenvolvimento degrada de forma intensa o ambiente, mas à medida que cresce economicamente e investe em educação ambiental a conscientização da sociedade pode transformar e reverter essa questão, de maneira a beneficiar o meio ambiente.

Segundo Ferreira (1998: p.101 apud MARTINS et al, 2013 p.27), “entre 1945 e 1980, a população brasileira percebeu elevadas taxas de crescimento econômico, o que causou profundas transformações estruturais no modelo social brasileiro. A sociedade rural, que se caracterizava na exportação de produtos primários de base agrícola, ficou no passado e emergiu a complexa sociedade 
urbano-industrial, a sociedade de risco". Neste contexto, é de suma importância a busca por alternativas sustentáveis, que mantenha o referencial de vida das pessoas que vivem na zona urbana, em especial das populações de baixa renda, e sua inserção na sociedade, buscando harmonizar o equilíbrio ambiental, pois, a própria natureza tem se revoltado por não respeitarem seus limites, devido ao desenvolvimento sem planejamentos.

Segundo Sheeffer (2008 p.6 apud COUTO et al, 2014 p.44), “a problemática ambiental poderá ser amenizada, mas não resolvida no atual modo de produção vistos que os custos sociais e ambientais fazem parte do moderno sistema produtor de mercadorias". Afirma o autor, dentro de tantos apelos ao consumo dificilmente o meio ambiente não será atingido, com essa atual produção excessiva que provoca escassez de recursos e matéria prima. Afirma Sheeffer (2008 p.8 apud COUTO et al, 2014: p.44), "este conceito não passa de uma falácia, uma fraude, visto que obscurece ou tenta obscurecer uma contradição fundamental: a finitude dos recursos naturais diante do caráter expansionista da sociedade industrial". Entende-se, que o autor não vê com credibilidade o modelo de sustentabilidade apregoado pelos empresários que ao tudo indica querem produzir e lucrar cada vez mais, e uma sociedade consumista que não resiste aos apelos de consumo.

\section{1 ÉTICA NAS ORGANIZAÇÕES}

A ética e a moral aplicada nas organizações vêm crescendo, diante de uma sociedade mais informada e exigente, faz-se, necessário adotar novos comportamentos e atitudes nas organizações.

Segundo Alonso (2006 p. 3-5):

Ética é a ciência da conduta, segundo o bem e o mal, com vistas à felicidade. È a ciência que estuda a vida do ser humano, sob o ponto de vista da qualidade da sua conduta. [...] Cada um vive em liberdade e todos buscam a felicidade. Precisamente esse dois polos liberdade e felicidade- se situa o comportamento moral.

A ética intitula-se a ciência ou a filosofia da conduta humana, a moral refere-se à qualidade dessa conduta humana. Segundo (ALONSO, 2006 p.141), “a atividade empresarial está integrada pela atividade tanto de operários quanto de administradores. A ética embebe todos os atos humanos, portanto está presente em todas as atividades da empresa".

Segundo Alonso (2006 p.144), "a ética empresarial implica criar tradição de cultura ética, que tende a crescer por si mesma, a empresa que encara frontalmente a sua vida ética cria uma energia interna que a guia para frente. Forma-se assim circulo virtuoso e enriquecedor". Entende-se então que, empresas éticas tendem sempre a ganhar com suas atitudes e práticas de boa conduta. Segundo Ashley (2005 p.4), 
"parece lícito afirmar, então, que hoje em dia as organizações precisam estar atentas não apenas as suas responsabilidades econômicas e legais, mas também às suas responsabilidades éticas, morais e sociais". Segundo a mesma, nos dias contemporâneos, as organizações precisam se preocupar com sua posição na sociedade, a forma como é vista pelo público, envolvendo sua lucratividade, pois o lucro moralmente aceitável é aquele conquistado com ética, sua participação na comunidade onde esta inserida.

De acordo com Ashley (2005 p.4):

Responsabilidades éticas correspondem às atividades, práticas, políticas e comportamentos esperados (no sentido positivo) ou proibidos (no sentido negativo) por membros da sociedade, apesar de não codificados em leis. Elas envolvem uma série de normas, padrões ou expectativas de comportamentos para atender aquilo que os diversos públicos (stakeholders) com as quais a empresa se relaciona e consideram legítimos, corretos, justos, ou de acordo com seus direitos morais ou expectativas.

As responsabilidades éticas da empresa correspondem ao comportamento esperado por seus membros, apesar de não estar escrito em nenhum artigo da lei, envolve normas e padrões a serem seguidos para atender seu público, de forma a satisfazer as expectativas dos mesmos.

Já a moral está relacionada a um processo de normas, que orientam o comportamento. A moral esconde-se em muitas escolhas e realizações no cotidiano empresarial, ainda que não se tenha consciência disso. As empresas investem em transmitir uma imagem ética, que envolve ser totalmente íntegras, em sintonia com a moral e os costumes. O comportamento antiético pode surgir nas organizações através de pessoas vistas como éticas essas podem cometer desatinos, por diversos fatores, relacionados à competitividade, quando pretende atingir determinadas posições na empresa sem se preocupar com os meios utilizados, colocando de lado os valores pessoais.

Conforme Ashley (2005 p.5), “a moral pode ser vista como um conjunto de valores e de regras de comportamento que as coletividades, sejam elas nações, grupos sociais ou organizações, adotam por julgarem corretas e desejáveis". Entende-se segundo a autora, que a definição de moral pode variar de acordo com o país, grupo social, ou organização. Depende da cultura e das regras adotadas por estes de acordo com o que julgam corretos.

Postura ética é determinada pelo comportamento do individuo, sua maneira de agir em sociedade, atribui-se, a uma maneira exemplar de viver, fundamentada em valores morais. É a conduta considerada correta. Distingue-se da moral, pois, esta se baseia na obediência a costumes e hábitos, a ética por sua vez, fundamenta-se nas ações morais. Os princípios éticos que norteiam o comportamento social se fazem presente também em certos grupos ou locais distintos, como: ética médica, ética na política, ética educacional, ética religiosa, entre outras.

A ética é um dos princípios básicos para alavancar uma carreira profissional de sucesso, pautada no respeito às pessoas. 
Já a postura antiética, é uma transgressão das normas estabelecidas em um código ético, comportamentos relacionados a uma postura antiética, corrupção, inveja, mentira, assedio moral, fofoca, entre outros, que venham a prejudicar o semelhante. $\mathrm{O}$ comportamento ético não muda de um instante para o outro, o individuo já nasce antiético, observa-se, que pessoas se escondem por trás da família, da religião, e transmitem uma boa postura, mas, tudo não passa de mera aparência. Pois, a postura ética não muda, não varia com o tempo e o lugar.

De acordo com Ashley (2005 p.5), "a ética afeta desde os lucros e a credibilidade das organizações até a sobrevivência da economia global'. Diante disso, entende- se que a postura antiética é prejudicial à organização, significa danos em longo prazo, em alguns casos, em curto prazo. Pois, essas quando descobertas abalam a imagem da empresa, algumas se recuperam de escândalos ligados a fraudes, adulteração de produtos, entre outros, em algumas empresas o impacto chega a ser devastador, diante de uma economia globalizada essa também é afetada.

De acordo com Dias (2004 p.194), "não existe uma nova ética. Ética é ética. Não existe nova, nem velha, existe a ética". Essa geralmente confundida com moral, a ética é interior e não se altera com o tempo ou o lugar, é pessoal esta na consciência, qualquer pessoa independente de onde vive condições sociais, sente quando age de maneira errada, através de intuições e sentimentos. Os princípios éticos despertam no individuo a necessidade e o dever de preocupar-se com as outras pessoas e toda forma de vida.

Segundo Alonso (2006 p.10), “a ética é objetiva e universal, transcende as pessoas". O autor defende que, a ética é algo pessoal característica de pessoas que tem um comportamento claro que vai ao ponto do que deseja dizer, está interiorizada no ser humano, não é algo relativo, mas sim, constante, segue sempre os mesmos princípios, os quais estão registrados no intimo. Esse defende que, os princípios da ética transcendem os indivíduos, refere-se, a algo estabelecido antes e acima da própria pessoa. Entendimento esse que ultrapassa o conhecimento empírico e cientifico.

De acordo com Alonso (2006 p.3), "a ética é a ciência da conduta humana, segundo o bem e o mal, com vistas à felicidade”. Esse defende que é uma ciência a qual estuda a vida do ser humano, a reação das pessoas diante de seus comportamentos, bons ou de má conduta, a relação da boa conduta e a felicidade no interior do ser humano. O mesmo afirma que a felicidade depende das ações do individuo. Essa ciência não estuda os costumes de um povo, mas sim, algo mais profundo a interioridade do ser humano.

Segundo Chiavenato (2003 p.604 apud LEAL et al, 2011 p.28), "a ética é o conjunto de valores ou princípios morais que definem o que é certo ou errado para uma pessoa, grupo ou organização". O autor defende que, o comportamento ético dentro de uma organização acontece quando, a mesma motiva seus 
colaboradores a comportarem-se eticamente, a ética preocupa-se com o comportamento, deve-se considerar a felicidade coletiva, e não somente a felicidade própria.

De acordo com Ashley (2005 p.3), “a preocupação com princípios éticos, valores morais e um conceito abrangente de cultura são necessários para que se estabeleçam critérios e parâmetros adequados para atividades empresariais socialmente responsáveis". Defende a autora que uma organização para exercer suas atividades empresariais de maneira socialmente responsável, depende dos princípios éticos, morais, e um entendimento de cultura que inclua todas as pessoas, não uma cultura direcionada a determinados grupos, e através desses serão estabelecidos métodos adequados para que a ação venha obter êxito.

Ainda conforme Ashley (2005 p.3):

Especificamente na área de ética e responsabilidade social, há muitos trabalhos interessantes que mostram preocupação com a cultura. Em administração, vários autores também estão se voltando, com freqüência para esses mesmos temas.

Entende-se, então que vários autores de diferentes áreas têm voltado à atenção e seus estudos para a cultura, e afirma-se, que a ética, a cultura, e os valores morais são simultâneos ao se falar de responsabilidade empresarial.

\subsection{EDUCAÇÃO AMBIENTAL NAS ORGANIZAÇÕES}

O termo educação ambiental, vêm sendo motivos de discussão e preocupação na sociedade e nas organizações. Há quem entenda que essa discussão é recente, mas, na verdade desde os primórdios de 1863, já havia a preocupação com o meio ambiente e os desgastes dos recursos naturais.

Segundo Dias (2004 p.75):

O diplomata George Perlcin Marsh publicava o livro "o homem e a natureza": ou geografia física modificada pela ação do homem, documentando como os recursos do planeta estavam sendo esgotados e prevendo que tais ações não continuariam sem exaurir a generosidade da natureza. Analisava as causas do declínio de civilizações antigas e previa um destino semelhante para as civilizações modernas, caso não houvesse mudanças.

Percebe-se, então a preocupação com a questão ambiental apresentada pelo diplomata em seu livro, a gravidade dos problemas ambientais, e uma necessidade da conscientização de toda sociedade. Entretanto, essa preocupação restringia-se a pequenos grupos de estudiosos, naturalistas, e apreciadores da natureza, entre outros. Atualmente as pessoas de um modo em geral preocupam-se com tal problema, mas, muitos não sabem o que e como fazer, para amenizar tal problema. 
Desde então, o Brasil já atraia a atenção de naturalistas de outros países, pela riqueza dos recursos naturais, tão propagada pelos colonizadores. Quando se refere à educação ambiental e analisa a historia do Brasil, observa-se, que a degradação vem de longas datas.

Conforme afirma Dias (2004 p.76):

No Brasil, em 1872, a princesa Isabel autorizava a operação da primeira empresa privada de corte de madeira (o ciclo econômico do pau-brasil encerrar-se ia em 1875, com o abandono das matas exauridas, e, em 1920, o pau-brasil seria considerado extinto.

Fatos assim aconteciam em varias partes do mundo, afetando de forma drástica o meio ambiente.

Conforme Dias (2004 p.76),

Patrick Geddes, considerado o pai da educação ambiental, expressava sua preocupação com os efeitos da Revolução industrial, iniciada em 1779, na Inglaterra, pelo desencadeamento do processo de urbanização e suas conseqüências para o ambiente natural.

Assim, passaram-se décadas, e os problemas ambientais se acumulavam, preocupando os grupos que se importavam com a causa. Os quais estavam certos, pois, as catástrofes começaram a acontecer no ano de 1952, na cidade de Londres, o estilo de vida desordenado do ser humano reflete no ar altamente poluído dessa cidade, provocando a morte de 1.600 pessoas, fato que atraiu a atenção do parlamento Inglês e do mundo, e estabeleceram a aprovação da lei do ar puro. Acontecimento este que desencadeou discussões em outros países, surgindo então o ambientalismo nos Estados Unidos, em 1960.

De acordo com Dias (2004 p.78), "a década de 60 começava exibindo ao mundo as consequências do modelo de desenvolvimento econômico adotado pelos países ricos". Ou seja, o então modelo capitalista de produção explora com excessividade os recursos naturais, e causam disparidades e desigualdades sociais, aumentando progressivamente os problemas ambientais. Nas grandes cidades níveis altos de poluição, despejos industriais nos rios, colocando em risco toda forma de vida, erosão, perda de fertilidade do solo, crescentes pressões sobre a biodiversidade, entre outros, afetando diretamente os recursos hídricos.

Percebe-se, então, a gravidade de tais fatos e a difícil reversibilidade. Fato esses, que atraiu a atenção de jornalistas, ambientalistas, e a sociedade civil em todo o mundo. Diante de todos esses fatos surge em vários países grupos e conferencias em defesa do meio ambiente, entre eles, "na Grã-Bretanha, em 1965, o termo Environmental education (Educação ambiental)”. Afirma (DIAS, 2004 p. 78).

Segundo Dias (2004 p.78), "em 1968, um grupo de especialistas de diversas áreas cria o então denominado clube de Roma”, o qual tinha como objetivo a discussão da crise instalada pelos problemas ambientais, e predizer como seria o futuro, caso não houvesse mudanças nos modelos de desenvolvimento econômico. Porém, a verdade política e técnica dos debates ocorridos no então Clube 
de Roma revelam claramente que a ideia delimitar o desenvolvimento sócio econômico não foi aceito. Em uma mesma época o clube de Roma e a conferência de Brundtland, apresentam um relatório o qual propõe o tema do eco desenvolvimento como possibilidade de ser realizado. Praticamente ao mesmo tempo surge um foco teórico que atesta limites e outros protegidos por organismos e agencias internacional, que defendem a sustentabilidade. Percebe-se, uma parte da sociedade preocupada com o meio ambiente e outra com o desenvolvimento sócio econômico. $\mathrm{O}$ eco desenvolvimento não passou de uma proposta, pois, esse não poderia sobreviver tendo alcance limitado somente às zonas rurais do cognominado terceiro mundo, devido a isso, não teve atenção dos interessados pela causa, de modo global.

Outro fato marcante foi da UNESCO (Organização das Nações Unidas para a Educação, a Ciência e a Cultura) pela causa ampliando o alcance para toda sociedade somando os termos desenvolvimento e respeito ecológico. No entanto, em poucos anos, surge o relatório de Brundtland, o mais importante dos últimos anos, este, teve alguns tópicos considerados principais como: a orientação para a sustentabilidade compatível ao desenvolvimento econômico, mas, dentro de medidas básicas para um progresso material sadio, tornar compatível desenvolvimento e combate a pobreza, através de uma melhor distribuição de renda, preservar a biosfera e a atmosfera. Esse não era mais um projeto restrito ao denominado terceiro mundo, mas, se estendia a toda sociedade.

Segundo Dias (2004 p.79) "O ano de 1972 testemunharia os eventos mais decisivos para a evolução da abordagem ambiental no mundo”. Alguns eventos e conferencias importante aconteceram, como "Conferência da ONU sobre o ambiente humano, ou Conferência de Estocolmo, como ficaria conhecida no mundo". ate que se chegasse a um consenso comum, de que o mundo necessitava de políticas de gerenciamento ambiental, e um programa internacional de educação ambiental.

Segundo Dias (2004 p. 79). “Os representantes dos países em desenvolvimento acusaram os países industrializados de quererem limitar seus programas de desenvolvimento, usando as políticas ambientais de controle de poluição como um meio de inibir a sua capacidade de competição no mercado internacional'. Nota-se, que alguns países, de modo especifico o Brasil, se preocupou mais com o crescimento do PIB (Produto Interno Bruto) do que com a degradação ambiental, descaso esse com a educação ambiental que permitiu o acontecimento dos problemas da época e se reflete atualmente no meio ambiente.

Conforme Dias (2004 p. 79). “A delegação brasileira chegou a afirmar que o Brasil não se importaria em pagar o preço da degradação ambiental, desde que o resultado fosse o aumento do seu Produto Interno Bruto". 
Após décadas de grandes batalhas dos ambientalistas e todos que se preocupavam com a causa, foi sancionada no Brasil, em 1981, a lei 6.938, que contribui como ferramenta de amadurecimento, implantação e consolidação da política ambiental no Brasil. Não obstante, a causa se depara com grandes resistências, impostas pelos países ricos para tornar possível a sustentabilidade, imposições essas vividas desde a década de 80, e chegam a ECO 92, causando impasses as novas propostas.

Esses mencionam a necessidade de compatibilizar o interesse industrial dos mesmos com a necessidade de sobrevivência da humanidade, seja pela preocupação com emprego, poder de compra, competição, ou outros, fez com que não aceitassem qualquer restrição a que viessem desfavorecer os custos de produção. Tais fatos repercutiram em todo mundo, como imposição a proposta central do ECO 92 do Rio, a agenda 21.

Conforme Dias (2004 p.84), “o Presidente João Figueiredo sancionava a lei 6.938, que dispunha sobre a política nacional do meio ambiente". Essa teve papel importante no progresso da educação ambiental, pois, a partir de então iniciativas e ações foram desenvolvidas em beneficio da causa.

Conforme Dias (2004 p. 92) No ano de 1994, com empenho e intervenção de diversos ministérios, elaboraram “o PRONEA (Programa Nacional de Educação Ambiental), dos quais os esforços culminaram com a assinatura pela Presidência da Republica a política nacional de educação ambiental (Lei 9.795 de 27/4/99)".

A partir de então, acelerou-se o ritmo ao processo de educação ambiental no Brasil. Nota-se que o Brasil fez alguns avanços melhorou seus índices de uma forma geral, mas, muito há para se fazer e melhorar nesse campo complexo, pois, estudos revelam a complexidade da questão ambiental, que deve compreender o próprio ambiente, esse envolve as áreas ecológicas, políticas, econômicas, Sociais, dentre outras.

Faz-se necessária, a mudança de postura das organizações no que se refere à educação ambiental, com o objetivo de reduzir a crise socioambiental, pela qual o mundo presencia há décadas.

Observa-se, que as organizações devem refletir e repensar, sobre seu desempenho e a sua relação com a competitividade frente a um mercado cada vez mais exigente em termos de responsabilidade ambiental, associando-as a ganhos de competitividade. Os crescentes problemas ambientais despertas atenção do consumidor em geral para uma maior conscientização da população, exigindo assim das organizações responsabilidades com a educação ambiental, com propostas voltadas para mudanças em seus hábitos, valores, costumes e crenças, de forma a minimizar os impactos ambientais.

Conforme Instituto Ethos de empresas e responsabilidade social:

Cabe à empresa ambientalmente responsável apoiar e desenvolver campanhas, projetos, e programas educativos voltados para seus empregados, para a comunidade e para públicos mais amplos, além de envolver-se em iniciativas de fortalecimento da educação 
ambiental no âmbito da sociedade como um todo. (ETHOS, 2003 p.4 apud ASHLEY et al, 2005 p.29).

Entende-se, então que a organização deve se preocupar com projetos que atenda não só seus membros e a comunidade onde está inserida, mas, a sociedade de um modo em geral, assim essa contribuirá com o desenvolvimento econômico, social, e ambiental de maneira ampla.

Tais ações favorecem a organização de várias formas, credibilidade e confiança dos consumidores, revertendo em ganhos de competitividade, redução dos custos com energia, água, matéria-prima, facilita a obtenção da ISO $14.001^{1}$, modifica de forma favorável a cultura da organização, comunidade, e beneficia o planeta.

Segundo Pelicioni (2005 p.10).

A educação ambiental deve, portanto, capacitar os indivíduos ao pleno exercício da cidadania, permitindo a formação A educação de uma base conceitual diversificada técnica e culturalmente, de modo a permitir que sejam superados os obstáculos a utilização sustentável do meio.

Afirma Pelicioni (2005), que, a educação ambiental deve ser capaz de transformar as atitudes do individuo a pratica da cidadania, a preocupação individual e coletiva para a melhoria da qualidade de vida ambiental. Nos níveis formais e informais tem procurado desempenhar esse difícil papel resgatando valores como o respeito à vida e à natureza. A mesma diz que, independente dos níveis, o objetivo é resgatar nas pessoas valores e respeito á vida e a natureza, entre outros, para que tenhamos uma sociedade mais igualitária, onde todos sejam felizes.

Conforme Souza (2000 p.19), "há varias dificuldades para conceituar educação ambiental”, esse afirma que, um dos agravantes, é as várias especialidades que envolvem o processo, pois, cada área defende sua teoria desviando a ação do foco principal. Entretanto, outros problemas dificultam o conceito de educação ambiental, entre esses os métodos de ensino, que devem ser distintos, para crianças e para adultos. Segundo o autor os problemas não se restringem a diferentes especialidades e métodos distintos, e sim na decisão de estratégias no que tange a finalidades, princípios e caminhos para seleção de conteúdos.

Conforme Dias (2004 p.98), “a evolução do conceito de educação ambiental esteve relacionada à evolução do conceito de meio ambiente e ao como este era percebido". Segundo esse o conceito de meio

ISO 14.001 é uma ferramenta criada para auxiliar empresas a identificar, priorizar e gerenciar seus riscos ambientais como parte de suas práticas usuais. A norma faz com que a empresa dê uma maior atenção às questões mais relevantes de seu negócio. Essa certificação permite a organização conquistar melhorias em seu desempenho ambiental global e nos negócios. 
ambiente relatava apenas os aspectos naturais, não permitindo a contribuição das ciências sociais, o entendimento e a busca por mudanças no comportamento de forma a contribuir com o ambiente humano.

Segundo Minini (2000 p.15-22 apud DIAS et al, 2004 p.99-100), “a educação ambiental é um processo que consiste em propiciar às pessoas uma compreensão critica e global do ambiente, para elucidar valores e desenvolver atitudes". Essa defende que, a educação ambiental precisa ser capaz de remeter o individuo a uma análise global e do meio onde vive. Essa conscientização deve transformar as atitudes e ações, e despertar valores, que leve a uma maior participação em beneficio da qualidade de vida, reduzindo assim a pobreza e o consumismo. Pois esses afetam diretamente o meio ambiente, e que o individuo seja capaz de perceber o quanto depende do mesmo.

\subsection{GESTÃO AMBIENTAL NAS ORGANIZAÇÕES COMO OPORTUNIDADE DE NOVOS NEGÓCIOS}

É notória a preocupação com a questão ambiental nos últimos anos. Diante da crescente degradação ao meio ambiente, exigindo assim, uma maior conscientização e mudanças de comportamentos para a preservação do mesmo.

Neste contexto, cabem as organizações um novo posicionamento em sua gestão que proporcionem crescimento econômico sem afetar a disponibilidade de recursos naturais para as gerações futuras.

Entretanto, muito se fez para que a gestão ambiental viesse a integrar as atividades das organizações, muitas conferências e movimentos aconteceram para se criar politicas, e uma lei de educação ambiental.

Conforme Dias (2004 p.82).

Realizar-se-ia de 14 a 26 de outubro de 1975, em Tibilisi, na Geórgia (ex-União Soviética), a primeira conferencia intergovernamental sobre educação ambiental, organizada pela UNESCO, em colaboração com o programa das Nações Unidas para o meio ambiente- Pnuma. Foi um prolongamento da conferencia das Nações Unidas sobre o ambiente humano (Estocolmo 1972), cujas implicações haviam de precisar, em matéria de educação ambienta.

Dias (2004) ainda relata que inúmeras conferências aconteceram para se conscientizar as organizações e a sociedade como um todo, da importância da educação ambiental para o planeta e para sobrevivência das espécies, incluindo a humana. Após 1972, como uma resposta das nações à questão ambiental inúmeros governos criaram medidas de proteção ao meio ambiente. A sociedade e a comunidade empresarial tornaram-se mais conscientes de forma que, a partir dos anos 80, perante uma sociedade mais consciente as questões de responsabilidade social são vistas como um mercado 
promissor, com novas oportunidades, pois, surgiram novos conceitos como eco desenvolvimento e desenvolvimento sustentável, uma linha de produção mais limpa, Gerenciamento Ambiental da Qualidade Total (TQEM), desenvolver novas tecnologias que permitam produzir mais com menos custos, melhor aproveitamento dos recursos naturais, entre outros.

Agregando assim, vínculos positivos entre a preservação ambiental e o crescimento econômico, empresas ambientalmente correta têm mais facilidade para obter a certificação da ISO 14.001, essa possibilita a empresa maior oportunidades no mercado interno e externo, oferece à organização uma reeducação ambiental a qual beneficiara a mesma com reaproveitamento de resíduos, melhora a eficiência reduzindo os custos, maior participação das partes interessadas e dos consumidores, dentre outros. Diante desta nova perspectiva, a preocupação com o meio ambiente passa a integrar o cenário da competitividade.

De acordo com Souza (1993 p.52 apud BERARDI et al, 2012 p.37), que no Brasil, "a constante pressão dos organismos internacionais, dos meios de comunicação e da sociedade fizeram com que algumas empresas se vissem compelidas a implementar programas ambientais”. Entende-se então, que as questões antes não observadas pelo público, atualmente exigem maior atenção. Para uma organização permanecer competitiva a gestão deve buscar novos métodos de produção que permita desenvolver economicamente com um mínimo de impacto ao meio ambiente.

Segundo Coraza (2003 p.3 apud SANTOS et al, 2006 p.2), “o gerenciamento ambiental envolve planejamento, organização e orienta a empresa a alcançar metas (ambientais) específicas em uma analogia, por exemplo, com que ocorre com a gestão da qualidade". Diz o autor que o SGA (Sistema de Gerenciamento Ambiental) é uma importante ferramenta que permite a organização manter relações com consumidores, companhias e minimizar os custos através de processos produtivos mais eficazes.

Conforme Walley e Withhead (1994 p.46-52 apud SANTOS et al, 2006 p.3), esses fundamentam sua teoria da seguinte explicação. "muitos administradores e estrategistas acabam se colocando numa cilada frente aos acionistas e o mercado, ao focarem nas "promessas-ilusórias" das soluções ganha a ganha. Tendo em vista, sobre tudo, o fato de que os custos oriundos das práticas verdes costumam suplantar, em muito, suas receitas”. Esses defendem que os administradores devem encontrar soluções de troca entre o mercado e o ambiente, consciente de que nem sempre se obtém retorno na dimensão esperada, os mesmos colocam a questão ambiental como um grande desafio, priorizando a gestão da organização, pois, cabe a essa buscar alternativas inovadoras para equilibrar custos com a questão ambiental e os retornos financeiros gerados pelos mesmos. Porém, nem todos os autores compartilham dessa ideia. 
Defende Sanches (2000 p.76-87 apud SANTOS et al, 2006 p.3 ), "as melhorias ambientais tem de ser vistas como uma oportunidade para tornar as empresas mais competitivas, e não apenas como uma fonte de custo". Esse defende que as organizações devem investir em melhorias ambientais como uma inovação, uma oportunidade dentro de um novo cenário competitivo, a gestão ambiental passa a ser uma ferramenta essencial para as organizações que pretendem manter-se em um mercado competitivo.

Segundo Porter e Linde (1995 p.72-78 apud SANTOS et al, 2006 p.3),

Os custos de adequação às legislações ambientais podem ser minimizados, ou até eliminados, através de inovações que tragam novos benefícios competitivos para as empresas. Novas posturas frente à questão ambiental podem dar inicio a um processo de inovação que diminua o custo total do produto ou aumente o seu valor agregado.

Observa-se, então que os autores Porter, Linde e Sanches compartilham da mesma ideia, porém, os descrevem com palavras diferentes.

De acordo com Miranda (1997 p.58-67 apud SANTOS et al, 2006 p.4),

Os SGA's têm se mostrado úteis a muitas organizações para auxiliar na melhoria dos seus processos produtivos. Este resultado é conseguido, na maioria das vezes, através de: 1) medidas de prevenção a danos ambientais- evitando além dos danos ao meio ambiente também a imagem da organização, como multas e indenizações; 2) economias de insumos- matéria prima e energia; 3) redução de desperdícios; e 4) desenvolvimento de tecnologias- como nova formula de tecnologias limpas.

Inicialmente a implantação de um SGA (Sistema de Gerenciamento Ambiental) na organização, pode ser fonte de custo para a mesma, como questionado por Walley e Withehead (1994). Entretanto, esse tem a possibilidade de colocar a empresa em vantagem competitiva, revertendo os custos em benefícios, este sistema de gerenciamento ambiental, através de suas políticas ambientais, possibilita melhorias no processo produtivo, arrecadação e retenção de custo, como argumentado anteriormente segundo a visão de Porter e Linde (1995) que defendem a obtenção de benefícios e vantagens, através de inovação na gestão ambiental.

No item três será apresentado o caminho metodológico deste estudo seguido da caracterização da empresa, assim como, da apresentação do recorte do relato de caso pré-existente, para posterior análise crítica.

\section{RELEITURA DO ESTUDO DE CASO}


Neste capítulo será apresentado o caminho metodológico deste estudo seguido da caracterização da empresa, assim como, da apresentação do recorte do relato de caso pré-existente, para posterior análise crítica.

\subsection{CAMINHO METODOLÓGICO}

Um caminho metodológico segundo Cervo et al. (2007:27) "é a ordem que se deve impor aos diferentes processos necessários para atingir um certo fim ou um resultado desejado". Dessa forma, a metodologia utilizada neste trabalho teórico foi dividida em quatro etapas, onde a primeira consiste em uma pesquisa quantitativa a partir de uma revisão bibliográfica, esta realizada com o objetivo de identificar como a empresa pode crescer economicamente dentro das práticas da sustentabilidade, entender como o desenvolvimento sustentável contribui com o equilíbrio ambiental, analisar como o desenvolvimento sustentável reduz os custos na organização, e identificar como o desenvolvimento sustentável atrai o consumidor.

Em um segundo momento, realizou-se um processo de seleção de um Estudo de Caso já existente no banco de dados do Google Acadêmico, cujo critério de seleção consiste na afinidade do estudo com a problemática abordada neste trabalho.

Como terceira etapa buscou-se encontrar um trecho do estudo de caso, cujo assunto abordado pudesse ser utilizado como fonte de pesquisa para realização da análise crítica, elaborada através da releitura de um recorte do estudo apresentado.

A quarta e última etapa deste processo metodológico sustenta-se a partir de Creswell (2007:46-47) que aponta como um caminho para a pesquisa qualitativa deste trabalho, uma vez que a "literatura é apresentada no final do estudo; ela se torna uma base de comparação e contraste de resultados no estudo qualitativo".

$\mathrm{O}$ autor ainda destaca que esta metodologia se encontra em projetos qualitativos onde se torna comum o embasamento da teoria com a realidade a partir da comparação entre as teorias apresentadas na fundamentação do estudo com as teorias encontradas no conteúdo analisado.

\subsection{CARACTERIZAÇÃO DA EMPRESA}

O estudo de caso escolhido para releitura trata-se de uma empresa que devido ao seu grau de representatividade no ramo de papel e celulose (primeira empresa do Brasil) a certificar seu inventário de Gases de Efeito Estufa (GEE) de acordo com a norma ISO 14.064, de 2006, e primeira empresa do 
Brasil, no setor de papel e embalagem, a ter créditos de carbono emitidos pelo protocolo de Kyoto. Após a busca em diversos sites acadêmicos que possuem informações sobre o assunto abordado o qual referência sobre a abordagem quantitativa usou-se os procedimentos de coleta de dados e de análise documental e de conteúdo, os quais foram realizados a partir dos dados secundários disponíveis nos relatórios de sustentabilidade e de demonstrações financeiras divulgadas pela empresa. Adicionalmente, foi entrevistado o gerente financeiro da organização por meio da aplicação de um roteiro de entrevista semi estruturada, para elucidar dúvidas e detalhar aspectos financeiros da organização. Satisfazendo assim, os objetivos da pesquisa, que foram descritiva e explicativa.

A empresa apresentada no relato de caso selecionado para este estudo situa-se em Vargem Bonita, uma cidade de Santa Catarina, com demais unidades em SC, RS, SP. Chama-se A Celulose Irani S.A, iniciouse em 1941 e é controlada desde 1994 pelo Grupo Habitasul. Os produtos produzidos pela Irani são celulose, papéis kraft, chapas e embalagens de papelão ondulado, madeira reflorestada, resinas e móveis de pinus, assegurando o fornecimento de produtos de alta qualidade e de base florestal renovável. Suas atividades se dividem em cinco unidades fabris, organizadas em três divisões: divisão de papel, de embalagens, de móveis e resinas, que também conta com uma fábrica de madeiras reflorestada, uma unidade de negócio, possui também escritórios em São Paulo e matriz em Porto Alegre. Até o ano de 2009, possuía 1756 colaboradores diretos, e produziram 185 mil toneladas de papel, obtendo uma receita bruta de R\$ 479,1 milhões (CELULOSE IRANI, 2009).

\subsection{RELATO DO CASO}

O presente estudo foi retirado banco de dados do Google Acadêmico, através de um Estudo de Caso intitulado de Tecnologias Ambientais e os Impactos no Desempenho Econômico-Financeiro: O Caso da Celulose Irani S/A. Estudo de Caso desenvolvido por Fábio Lazzarotti, Simone Sehnem, Yeda Maria Pereira Pavão, Anete Alberton, Sidnei Marinho. Em abril de 2014. A partir desse estudo fez-se o recorte da página 69 à página 76 apresentado a seguir.

"A Celulose Irani desenvolve o seu trabalho com a preocupação da sustentabilidade ambiental, que se operacionaliza por meio de diversas práticas: manejo das florestas até a disposição final dos seus produtos; geração de riqueza e renda, associada à atividade produtiva sustentável; produção a partir de matéria-prima renovável ou reciclada (florestas plantadas e aparas); coleta e tratamento adequados da água, com uso de energia limpa, gerada por meio de fontes renováveis (hidroelétrica e termoelétrica, à base de biomassa); estação de tratamento de efluentes; balanço neutro de carbono (cada hectare de floresta plantada captura aproximadamente oito toneladas de carbono por ano da atmosfera, o que contribui para a diminuição do aquecimento global). Todo esse trabalho foi reconhecido pela sociedade em 2009, por meio das seguintes premiações":

- 11 $1^{\circ}$ Prêmio Empresa Cidadã ADVB/SC - ADVBSC: Associação dos Dirigentes de Vendas e Marketing de Santa Catarina (Categoria Preservação Ambiental); Prêmio Fritz Muller (realização da Fatma);

- $5^{\circ}$ Prêmio Brasil Ambiental Categorias MDL (realização AMCHAM-RIO - Câmara de Comércio Americana do Rio de Janeiro); Prêmio Benchmarking Ambiental Brasileiro (realização Mais Projetos);

- Prêmio Expressão de Ecologia (Categoria Controle da Poluição Setor Papel e Celulose);

- Prêmio FEBRAMEC 2009 - Feira Brasileira da Mecânica e Automação Industrial (Categoria Emissão Atmosférica Gases de Efeito Estufa (GEE));

- Prêmio Reabilitação Profissional 2009 (Case Panorama da Reabilitação Profissional na IRANI); e

- Prêmio Responsabilidade Social 2009 (Realização da Assembleia Legislativa do RS).

Conforme o relatório de Sustentabilidade da Celulose Irani (2008), aproximadamente 75\% da demanda energética da empresa foi suprida pela auto produção proveniente de três hidroelétricas próprias, localizadas no entorno do parque fabril, somadas a 
uma hidroelétrica movidas a biomassa. A biomassa consiste em resíduos florestais produzidos na empresa e por indústrias madeireiras na região.

Esses resíduos são convertidos em energia a partir da sua queima como combustível na usina de cogeração. Trata-se da produção de energia limpa. Consequentemente houve uma redução do consumo de óleo de baixo ponto de fluidez (BPF) em 97\% no período de 2004 a 2008, e foram eliminados os geradores à base de óleo. De acordo com a Celulose Irani (2008), essa ação reduziu significativamente a emissão de GEE.

O Projeto de Inventário de Emissões de GEE realizado pela empresa anualmente, procura identificar as emissões e sumidouros, assim como avaliar o potencial da Irani em relação ao "Carbono Zero", isto é, verificar se a empresa é neutra na emissão de dióxido de carbono, sendo esse processo certificado pela ISO 14064: 2006. Isso comprova que as atividades produtivas da Irani retiram mais carbono da atmosfera do que emitem, tornando a organização Carbono Neutro. O principal fator que contribuiu para diminuir as emissões diretas foi a ETE da unidade de papel, que reduziu a emissão de metano (CELULOSE IRANI, 2008). A Ira MDL de pequena escala. De acordo com o Relatório de Sustentabilidade da Celulose Irani (2008, p. 48) "os projetos de MDL possibilitam reduzir a emissão de cerca de 200 mil toneladas de CO2 e ao ano".

O Projeto da Usina de Cogeração está registrado na ONU sob a terminologia "Irani Biomass Electricity Generation Project" e foi aprovado em 7 de julho de 2006. Esse projeto consiste em geração de eletricidade renovável, que substitui a energia fornecida pela concessionária estadual. Evita a produção de metano pela utilização de combustão controlada de biomassa. Os insumos usados para gerar energia de resíduos na Usina de Cogeração são originários de base florestal que substituem o uso de recursos naturais não renováveis. Esse procedimento permite reduzir as emissões de gases poluentes, como dióxido de carbono e metano, gerados em maior quantidade na queima de combustíveis fósseis.

A implantação desse projeto permitiu a redução atestada de gases poluentes. As Reduções Certificadas de Emissões (CER), obtidas entre 2005 e 2008, totalizaram 567.214 toneladas de CO2e (equivalent carbon dioxide). Levando-se em conta a média obtida nos últimos dois anos, a estimativa de redução de emissão de gás carbônico pela Irani em 21 anos é de aproximadamente 3.321.885 toneladas de CO2e (CELULOSE IRANI, 2008)".

A Modernização da Estação de Tratamento de Esgoto (ETE) foi o primeiro projeto no mundo de tratamento de efluentes totalmente aeróbicos aprovados pela ONU. A degradação anaeróbica (sem oxigenação) foi substituída pela aeróbica (com oxigenação) da matéria orgânica, o que evita a emissão de metano, um gás de efeito estufa responsável pelo aquecimento global. Esse sistema baseia-se no tratamento secundário a partir do lodo ativado com aeração prolongada, o que contribui para que o lodo não se deposite no fundo da lagoa e gere metano. "As Reduções Certificadas de Emissões (CER) obtidas entre 2007 e 2008, totalizaram 59.807 toneladas de CO2e. Considerando-se a média obtida em 2008, a estimativa de redução de emissão de gás carbônico pela Irani em 21 anos, decorrente desse projeto, é de aproximadamente 821.100 toneladas de CO2e" (CELULOSE IRANI, 2008, p. 49)".

\section{Investimentos em Tecnologias Ambientais e Desempenho Econômico-Financeiro da Empresa}

Neste tópico apresentam-se e discutem-se os investimentos em tecnologias ambientais; a evolução dos indicadores baseados nos valores econômicos (EVA - Economic Value Added) e (MVA - Market Value Added) e na geração de caixa (EBITDA Earnings Before Interest, Taxes, Depreciation and Amortization); os indicadores de rentabilidade (ROA - Return On Assets, ROI - Return On investment e ROE - Return On Equity), em relação ao período de análise. Na Figura 1, são mostrados os investimentos totais em tecnologias ambientais, com destaque para os projetos 'usina de cogeração de energia' e 'modernização da estação de tratamento de efluentes, realizados pela empresa desde 2003. Para cada projeto indicam-se também os resultados dessas tecnologias e os créditos de carbono, que são receitas advindas de ambos os projetos aprovados pela ONU.

Figura 1 - Investimentos em Tecnologias Ambientais (2003-2009) e Créditos de Carbono (Receitas anuais).

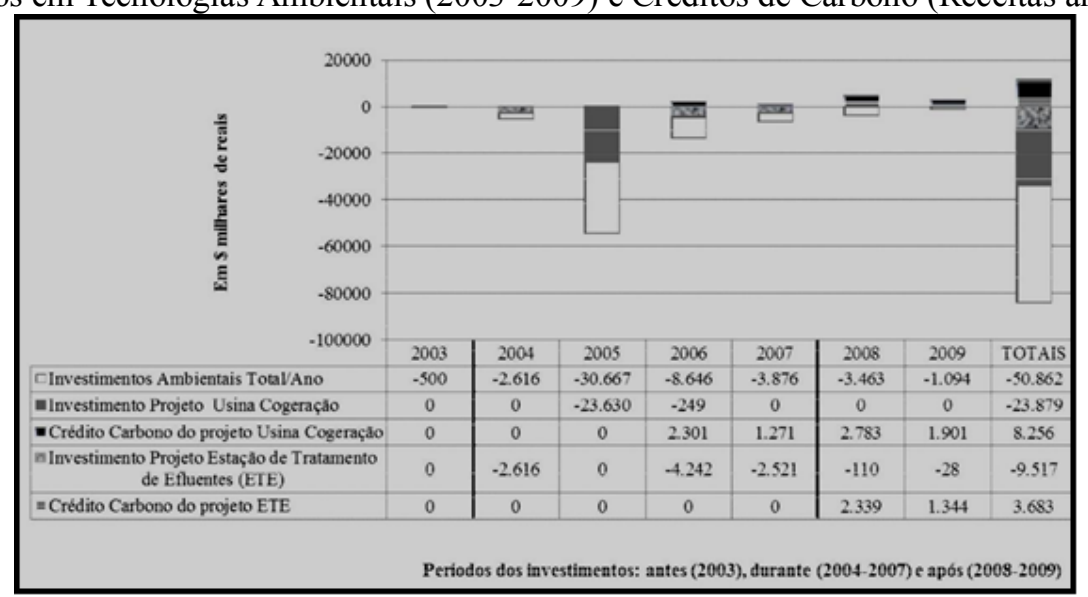

Pela Figura 1 é possível constatar que do total de investimentos em tecnologias ambientais realizados pela empresa, desde 2003, aproximadamente 70\% corresponde aos projetos usina de cogeração e modernização da estação de tratamento de efluentes (ETE), sendo o primeiro o de maior investimento. Entretanto, a partir de 2006, começaram a ingressar os créditos de 
carbono do projeto da usina de cogeração. É a partir desse momento que a Celulose Irani passa a receber os primeiros retornos financeiros dos investimentos ambientais despendidos durante o período de implantação. Em relação ao projeto de modernização ETE, os créditos de carbono iniciam em 2008. A evolução dos indicadores baseados no valor econômico e na geração de caixa, em relação aos períodos de investimentos em tecnologias ambientais, é apresentada na Figura 2.

Figura 2 - Evolução dos indicadores baseados no valor econômico e na geração de caixa em relação aos períodos de investimentos em tecnologias ambientais.

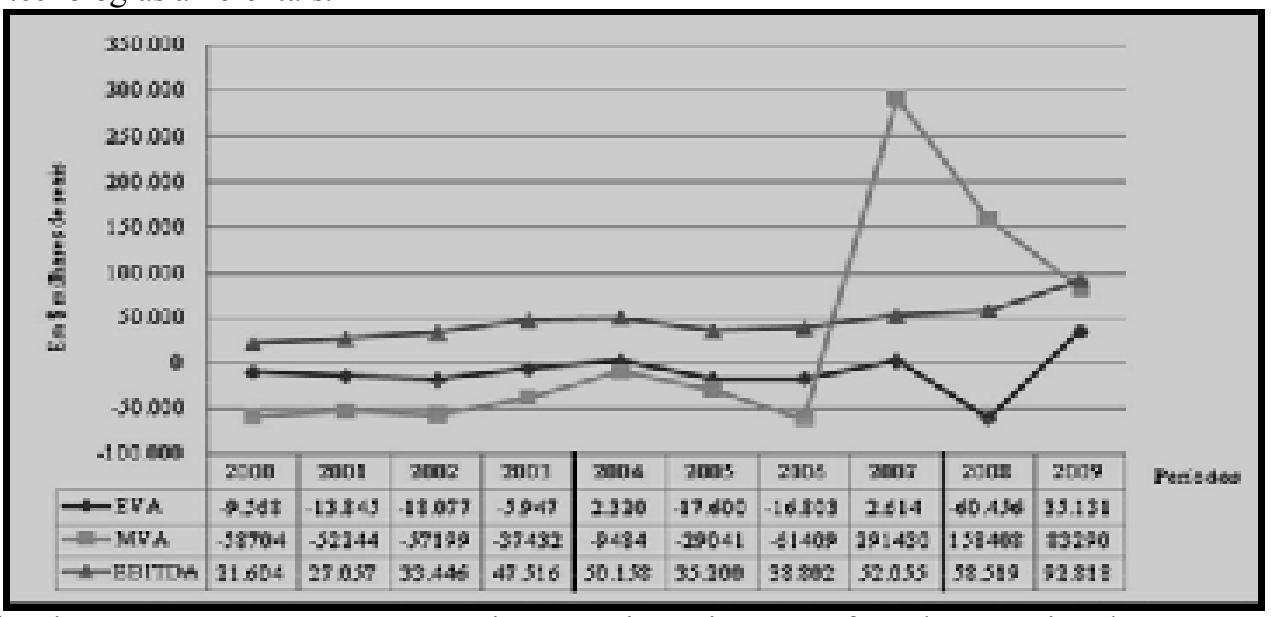

Na Figura 2, evidencia-se que nos quatro anos anteriores aos investimentos efetuados na usina de cogeração e na estação de tratamento de efluentes, isto é, no período de 2000 a 2003, a Celulose Irani S.A. obteve um EVA negativo. Durante o período de investimentos ambientais, ou seja, de 2004 a 2007, as oscilações do EVA foram abruptas, correspondendo a uma variação de R\$ 2.320 mil em 2004 para R\$ 17.600 mil em 2005; e ainda R\$ 16.803 mil no ano de 2006 e um comportamento positivo de R\$ 2.614 mil em 2007. Observa-se que essas variações estão associadas ao lucro do exercício da empresa. Em 2005 e 2006, o lucro teve uma forte redução em relação aos anos anteriores, o que causou impacto no EVA.

De acordo com o relatório da administração, publicado nos balanços de 2005 e 2006, a excessiva apreciação do Real nesse período ocasionou maior oferta de produtos no mercado interno, que refletiu em uma queda significativa nos preços e nas margens líquidas, impactando fortemente no resultado da Irani. No período seguinte, após os investimentos ambientais (20082009), é verificado um padrão ainda mais súbito, de R\$ 60.456 mil em 2008 para R \$ 35.131 mil em 2009, que - na percepção do entrevistado - está associado à crise financeira internacional e à conclusão do Projeto Superação, em 2008, onde foram alocados R\$ 160,8 milhões na modernização das fábricas de papel e embalagem. Nota-se que o resultado do EVA desse último ano foi o maior em todos os períodos analisados.

Portanto, ficou evidenciado que o valor do EVA sofreu alterações que não permitem estabelecer um padrão histórico de evolução nos períodos analisados. A variação foi grande e discrepante, o que dificulta a verificação e a afirmação da existência de uma tendência central, isto é, um padrão de comportamento ascendente ou descendente ao longo dos anos em relação aos períodos de investimentos nas tecnologias ambientais. O MVA mostra um comportamento similar ao EVA na maioria dos períodos, porém com um crescimento expressivo em 2007 e, embora tenha se reduzido nos anos seguintes, 2008 e 2009, o indicador manteve-se positivo.

Tais resultados são similares aos encontrados por Santos e Watanabe (2005), que elucidaram em seu estudo uma diferença fundamental entre os índices EVA e MVA. Enquanto o primeiro índice se baseia nos demonstrativos contábeis e reflete o desempenho passado da empresa, o segundo revela a visão do mercado de capitais, incorporando a expectativa de resultados futuros da companhia. Os autores salientam que, em princípio, não há uma relação direta entre o EVA passado da organização e o MVA.

Mas, caso uma empresa apresente uma melhora no EVA apurado num determinado período e o mercado entenda que essa melhora vai perdurar no futuro, então esse acréscimo de performance deverá se refletir imediatamente no MVA da empresa, o que parece ter ocorrido na Celulose Irani S.A.

De acordo com o entrevistado e com base nos balanços financeiros de 2006 e de 2007 (além dos respectivos balanços sociais e relatórios de sustentabilidade), a empresa informou o mercado sobre os resultados advindos do projeto de cogeração de energia sob a forma de créditos de carbono e sobre o 'Projeto Superação', que incluía investimentos em tecnologias ambientais visando a otimização de recursos existentes, além dos benefícios ambientais. Acerca do comportamento do EBITDA, nos anos de 2000 a 2009, é possível constatar, na Figura 3, que esse indicador mais que quadruplicou no período, passando de R 21.604 mil para R 92.818 mil. Evidencia-se também que essa evolução se deu ano a ano, com exceção de 2005, quando houve uma queda de 70,18\% em relação ao EBITDA de 2004, que retomou o crescimento em 2006. Análogo ao comportamento verificado no MVA, o EBITDA também parece ter sido influenciado pelas tecnologias ambientais, principalmente no período após os investimentos. Essa inferência encontra suporte no conceito do EBITDA, o qual indica se os ativos operacionais estão gerando caixa. Como a usina de cogeração e a ETE resultaram em créditos de carbono, cujas receitas advindas dos projetos iniciaram já em 2006, presume-se que parte do crescimento do EBITDA tenha relação com esses ativos. 
Todavia, essas evidências não podem ser comprovadas suficientemente apenas com os dados coletados e analisados neste artigo. Outras variáveis ou externalidades, como o Projeto Superação, salientado anteriormente, podem ter contribuído para o alcance desse comportamento nos períodos analisados, sobretudo no período considerado após os investimentos nas tecnologias ambientais. A Figura 3 apresenta a evolução dos indicadores de rentabilidade em relação aos períodos de investimentos em tecnologias ambientais.

Figura 3 - Evolução dos indicadores de rentabilidade em relação aos períodos de investimentos em tecnologias ambientais.

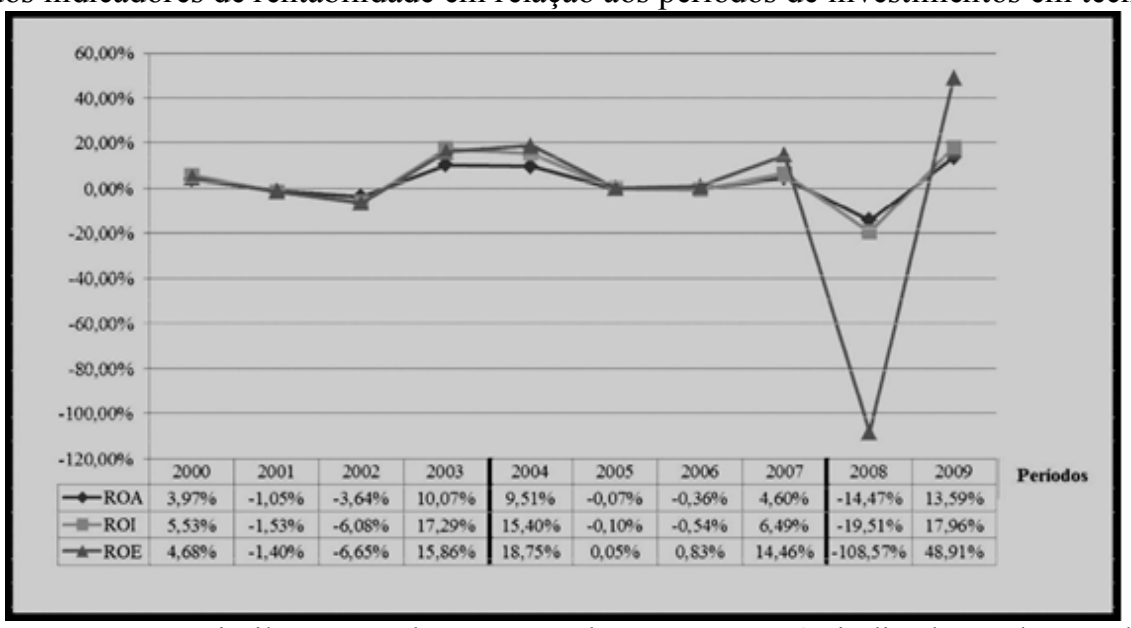

Nota-se que há um comportamento similar, em todos os períodos, entre os três indicadores de rentabilidade analisados. O ROA variou de 3,97\% em 2000 para $13,59 \%$ em 2009, ao passo que o ROI variou de 5,53\% para 17,96\%. A maior variação ocorreu com o ROE, que estava com 4,68\% em 2000 e evoluiu para um índice de 48,91\% em 2009. Por outro lado, esse mesmo indicador, após finalizar os investimentos ambientais em análise, apresenta também a maior queda (108,57\%). Inferese, pois, que essa discrepância, se comparada aos anos anteriores, pode estar associada à crise financeira internacional, que impactou negativamente em todas as atividades econômicas, assim como à desvalorização do real, principalmente no ano de 2008.

De toda forma, esse conjunto de indicadores parece ser menos sensível aos investimentos em tecnologias ambientais, comparativamente aos indicadores baseados no valor econômico e de geração de caixa, com destaque para o MVA e o EBITDA. Embora o ano de 2008 tenha sido atípico ao longo do período estudado, não é possível identificar um padrão de associação dos indicadores de rentabilidade em relação aos diferentes períodos de implantação dos projetos de MDL analisados. Esse resultado converge para o achado de estudos anteriores, como Wagner et al., (2002) e Thornton, Kagan e Gunningham (2003), que também estudaram investimentos ambientais e desempenho financeiro em indústrias de papel, medido pela rentabilidade, e não encontraram relação entre essas variáveis.

\subsection{ANÁLISE CRÍTICA}

Observa-se através deste estudo que é possível compatibilizar crescimento econômico e sustentabilidade, através de inovação nos processos de produção, desenvolvimento de novas tecnologias que possibilitem uma produção mais limpa, a implementação destes inicialmente geram custos, baixando assim o caixa operacional da organização. Entretanto iniciativas como usinas de cogeração de energia, estação de tratamento de efluentes, e produção com matéria-prima renovável, dentre outros Mecanismos de Desenvolvimento Limpo (MDL), citados na empresa do estudo de caso irão beneficiar o ambiente, segundo indicadores que medem o desempenho econômico-financeiro da empresa esses impactaram de forma favorável ao longo prazo, através de vantagem competitiva, redução nos custos, valorização do patrimônio, das ações e criação de valor.

Segundo Porter e Linde (1995 p.72,78 apud SANTOS et al, 2006 p.3),

Os custos de adequação às legislações ambientais podem ser minimizados, ou até eliminados, através de inovações que tragam novos benefícios competitivos para as empresas. Novas posturas frente à questão ambiental podem dar início a um processo de inovações que diminua o custo total do produto ou aumente o seu valor agregado.

Ao se tratar de responsabilidades sociais e ambientais, a empresa citada não atende somente os requisitos legais, essa vai além. Observa-se, facilmente os princípios éticos, os valores morais e a cultura predominante na empresa, através de suas práticas de sustentabilidade, o respeito e a responsabilidade ao 
tratar das questões ambientais, tais atitudes têm uma repercussão positiva para a organização, pois, nos dias atuais a empresa não pode se preocupar somente com os quesitos econômicos.

Segundo Ashley (2005 p.4), "parece lícito afirmar, então, que hoje em dia as organizações precisam estar atentas não apenas as suas responsabilidades econômicas e legais, mas as suas responsabilidades, morais e sociais".

Ao buscar novos métodos de produção como o uso de matéria-prima renovável ou reciclada, plantio de árvores nativas para retirada de carbono da atmosfera obtendo crédito de carbono emitido pelo protocolo de Kyoto, nota-se o diferencial da educação ambiental dos gestores dessa organização, a preocupação coletiva ao buscar soluções na própria natureza sem agredi-la, mas de maneira renovável, uma conscientização para melhoria da qualidade de vida.

Segundo (PELICIONI, 2005: p.10).

A educação ambiental visa capacitar os seres humanos ao exercício da cidadania, a preocupação individual e coletiva para melhoria da qualidade de vida ambiental. Procurando modos de superar obstáculos a utilização dos recursos disponíveis na natureza, faz-se presente o resgate dos valores, como respeito à vida, tornando possível uma sociedade mais justa.

Conforme Souza (1993 p.52 apud BERARDI et al, 2012 p.37), que no Brasil, “a constante pressão dos organismos internacionais, dos meios de comunicação e da sociedade fizeram com que algumas empresas se vissem compelidas a implementar programas ambientais".

Ao implantar novos sistemas de geração de energia e melhor aproveitamento da água, sendo a primeira empresa de celulose brasileira a obter créditos de carbono, posturas e processos que beneficiam o ambiente a empresa atrai a atenção do consumidor de forma positiva.

Segundo Brown (2003 p.14 apud NASCIMENTO et al, 2012).

Que a economia está em conflito com os sistemas naturais do planeta é uma evidência que ressalta das informações cotidianas sobre o desaparecimento das zonas de pesca, a redução das florestas, a erosão do solo... e o desaparecimento das espécies.

Cabe ressaltar, nem todas as organizações têm a consciência da necessidade de conciliar crescimento econômico e sustentabilidade, uma vez que o planeta revela a gravidade das agressões e sua difícil reversibilidade. A empresa citada no estudo de caso tem uma visão de que os cuidados com o ambiente devem ser feitos de forma desinteressadas e não somente visando ganhos econômicos, esses virão em longo prazo, assim evidenciados pela mesma.

\section{CONCLUSÃO}

Quanto ao objetivo geral desse estudo que foi o de identificar como a empresa pode crescer economicamente dentro das práticas da sustentabilidade, através do desenvolvimento de novas tecnologias que permitem uma maior produção utilizando menos matéria prima e a redução de recursos naturais como energia e água, adequarem-se a realidade e buscar alternativas como destinar corretamente os resíduos assim o que seria descartado passam a ser mais uma fonte de renda. Empresas que agem corretamente dentro das políticas e leis ambientais não têm despesas com multas. Conclui-se que, com o advento da Revolução Industrial e o crescimento econômico desordenado, iniciam-se os problemas ambientais afetando todo o planeta. Os ambientalistas e defensores da causa lutam em prol da conscientização da sociedade e das organizações pela necessidade da preservação.

A partir da década de 1960 houve uma maior conscientização da sociedade em relação às questões ambientais, entretanto, a década de 70 revela um grande desafio a ser enfrentado pelos defensores da causa, diante dos políticos e empresários que até então, percebiam a sustentabilidade como sendo contrária ao crescimento econômico. Após grandes esforços a década de 80 evidencia uma nova visão da comunidade empresarial em relação à sustentabilidade, observam-se novas oportunidades, entre essas, vantagem competitiva e a credibilidade diante de seus stakeholders, a possibilidade de compatibilizar crescimento econômico e sustentabilidade. 
No entanto, percebe-se a necessidade da inserção de educação ambiental no âmbito coletivo visando mudanças de comportamento dos indivíduos e organizações, pois com o crescimento da população mundial e os apelos ao consumo, estes geram uma produção excessiva ocasionando o risco de escassez de recursos e matéria-prima que viriam a atender as necessidades das futuras gerações.

Após este estudo conclui-se que, diante de tantos desafios é possível o equilíbrio entre o crescimento econômico e o desenvolvimento sustentável, evidenciados conforme o estudo de caso.

\section{REFERÊNCIAS}

ALMEIDA, Fernando. Crescer com sustentabilidade. 2005. Fundação Nacional da Qualidade. Disponível em: http://www.fnq.org.br/download/classe_mundial/pdf05.pdf. Acesso em: 20 mai. de 2016.

ALONSO, Félix Ruiz. LÓPEZ, Francisco Granizo. CASTRUCCI, Plínio de Lauro. Curso de ética em administração. São Paulo: Atlas, 2006.

ASHLEY, Patrícia Almeida (coordenação). Ética e responsabilidade social nos negócios. 2. Ed. São Paulo: Saraiva 2005.

BELLEN, Hans Michael Van. Desenvolvimento Sustentável: uma descrição das principais ferramentas de avaliação. 2004. Disponível em: www.scielo.br/scielo.

php?script=sci_arttext\&pid=S1414-753X2004000100005

Acesso em: 05 mai. 2016.

BERARDI. Pátricia Calicchio. A Evolução do conceito de governança corporativa à luza da ética: uma análise longitudinal. 2008. Disponivel em:

bibliotecadigital.fgv.br/dspace/bitstream/.../Tese\%20PBERARDI\%20maio\%202012.pdf?..Acesso em: 15 jun.2016.

CERVO, Amado L. et al. Metodologia científica. 6 ed. São Paulo: Pearson Prentice Hall, 2007.

CRESWELL, John W. Projeto de Pesquisa: Métodos qualitativo, quantitativo e misto. Porto Alegre: Artmed, 2007.

CRESWELL, John W. Investigação qualitativa e projeto de pesquisa: escolhendo entre cinco abordagens. 3. Ed. Porto Alegre. Penso, 2014. 341p.

COUTO, Elení Pereira. Desenvolvimento (IN) Sustentável - Centro Científico Conhecer. 2014.

Disponível em:

www.conhecer.org.br/enciclop/2014c/pdf/desenvolvimento.pdf- Acesso em: 01 jun 2016.

DIAS, Genebaldo Freire. Educação ambiental: Princípios e práticas/ Genebaldo Freire Dias-9. Ed- São Paulo: Gaia, 2004.

ESTENDER, Antonio Carlos. Estratégias de desenvolvimento sustentável estudo de caso: Grupo

Itaú- Unibanco. 2010. Disponível em:

revistas.ung.br > Capa > Vol. 4, No 1 (2010) > Estender

Acesso em: 10 jun. 2016. 
INBS. Relatório Brundtland. Definição e princípios. Disponível em:

http://www.inbs.com.br/ead/Arquivos\%20Cursos/SANeMeT/RELAT\%23U00d3RIO\%20BRUNDTLAN D\%20\%23U201cNOSSO\%20FUTURO\%20COMUM\%23U201d.pdf. Acesso em: 25 mai. de 2016.

IRANI, Celulose S.A.. Release de Resultados - 4 T09 e 2009. Disponível em:

http://www.irani.com.br/uploads/informacao_financeira_ri/bbleed7dd2c118d6cfffaa $77 f c e 6 a 232 f 6651 \mathrm{ca}$ 9.pdf. Acesso em: 15 jul. de 2016.

LAZZAROTTI, Fábio; SEHNEM, Simone,; et al. (2014). Tecnologias ambientais e os impactos no desempenho econômico-financeiro: $o$ caso da Celulose Irani S/A. Disponível em: http://www.spell.org.br/documentos/ver/29930/tecnologias-ambientais-e-os-impactos-no-desempenhoeconomico-financeiro--o-caso-da-celulose-irani-s-a. Acesso em: 5 mai. de 2016.

LEAL, Édia Medeiros. A Comunicação externa como fator determinante para firmar parcerias empresariais no terceiro setor. 2011. Disponível em: http://www.leg.ufpi.br/subsiteFiles/admpicos/arquivos/files/EDIA\%20MEDEIROS\%20.pdf Acesso em: 15 mai. 2016.

MARTINS, Sara Lucia. A proporcionalidade no licenciamento ambiental: um estudo a partir do caso empreendimento Hotel marina parque ponta do coral. 2013. Disponível em: https://repositorio.ufsc.br/bitstream/handle/.../Monografia_Versão_Final.pdf?sequence... Acesso em: 05 mai. 2016.

NASCIMENTO. Elimar pinheiro do. Trajetória da sustentabilidade: do ambiental ao social, do social ao econômico. 2012. Disponível em: www.scielo.br/scielo. php?script=sci_arttext\&pid=S010340142012000100005 - Acesso em: 12 jun. 2016.

PELICIONI, Maria Cecília Focesi; PHILIPPI JR., Arlindo. Educação ambiental e sustentabilidade. Barueri, SP: Manole, 2005. - (Coleção ambiental; 3).

Revista Canção Nova. Ano XIII- No 186- jun. de 2016.

SANTOS, Débora Oliveira. Sistema de gestão ambiental, sustentabilidade e vantagem competitiva: em busca de uma convergência. 2006. Disponível em: www.abepro.org.br/biblioteca/enegep2006_tr520346_7976.pdf Acesso em: 10 mai. 2016.

SOUZA, Nelson Mello. Educação ambiental: dilemas da prática contemporânea / Nelson Mello e Souza. - Rio de Janeiro: Thex Ed: Universidade Estácio de Sá, 2000.

THORNTON, D.; KAGAN, R. A.; GUNNINGHAM, N. Sources of corporate environmental performance. California Management Review, v. 46, n. 1, 2003.

WAGNER, M.; VAN PHU, N.; et al. The relationship between the environmental and economic performance of firms: an empirical analysis of the European paper industry. Corporate SocialResponsibility and Environmental Management, v. 9, n. 3, p. 133-146, Sept. 2002. 
Miranda, Medeiros et al.

Recebido em: 09/08/2016

Aceito em: 22/09/2016

Nome: Macsuel Miranda de Oliveira

(c) (†)

e-mail: macsuelmiranda@gmail.com

Este obra está licenciada com uma Licença Creative

Commons Atribuição 4.0 Internacional. 